\title{
Conomics
}

The Open-Access, Open-Assessment E-Journal

Discussion Paper

No. 2011-17| June 14, 2011 | http://www.economics-ejournal.org/economics/discussionpapers/2011-17

\section{A Shapley Value Approach to Pricing Climate Risks}

\author{
Roger M. Cooke \\ Resources for the Future and Delft University of Technology
}

\begin{abstract}
This paper prices the risk of climate change by calculating a lower bound for the price of a virtual insurance policy against climate risks associated with the business as usual (BAU) emissions path. In analogy with ordinary insurance pricing, this price depends on the current risk to which society is exposed on the BAU emissions path and on a second emissions path reflecting risks that society is willing to take. The difference in expected damages on these two paths is the price which a risk neutral insurer would charge for the risk swap excluding transaction costs and profits, and it is also a lower bound on society's willingness to pay for this swap. The price is computed by (1) identifying a probabilistic risk constraint that society accepts, (2) computing an optimal emissions path satisfying that constraint using an abatement cost function, (3) computing the extra expected damages from the business as usual path, above those of the risk constrained path, and (4) apportioning those excess damages over the emissions per ton in the various time periods. The calculations follow the 2010 US government social cost of carbon analysis, and are done with DICE2009.
\end{abstract}

Paper submitted to the special issue

The Social Cost of Carbon

JEL C71, Q54

Keywords Climate change; insurance premium; Shapley value; DICE

Correspondence Roger M. Cooke, Chauncey Starr Chair for Risk Analysis, Resources for the Future, 1616 P St. NW, Washington DC 20036-1400, USA, e-mail: cooke@rff.org 


\section{Introduction}

Reducing carbon emissions not only reduces the damages resulting from global temperature rise, it also reduces the probability of catastrophic climate change. Individuals are generally risk averse, and various authors have suggested that society should be willing to pay a "risk premium" to reduce these catastrophic risks. A recent review (Kousky et al 2011) finds very few papers that calculate an explicit risk premium. Some authors suggest that no risk premium is necessary (Mendelsohn 2008, Nordhaus 2007), others speculate that a risk premium of $50 \%$ of the social cost of carbon is not out of the question (Yohe and Tol, 2008). Most approaches make assumptions about the form of a social welfare or social utility function. Given the difficulties inherent in viewing climate change as a social utility optimization problem, ${ }^{1}$ some authors have suggested that the climate change problem be viewed through the lens of insurance or risk management (e.g., Weitzman 2009).

In view of the diversity of methods and putative values, it is perhaps useful to take a different fix on the problem based on a very different point of departure. Foregoing any attempt to quantify a social utility function, this approach follows Anderson and Bows (2011) by interpreting various international agreements as expressions of society's desire to trade the current climate risk along the BAU path for the risk along an emissions path that satisfies a risk constraint: the probability of raising mean temperature by more than $2^{\circ} \mathrm{C}$ in 200 years should not exceed 19\%. Risk trading transpires in insurance markets in which a risk neutral insurance company and a risk averse customer agree to a risk swap. Instead of postulating a social utility function and computing how much society should be willing to pay, the expressed social preference for a swap is used to infer a lower bound on what society is willing to pay. This lower bound is the price that a risk neutral insurer would charge for the swap excluding transaction costs and profit, namely the difference in expected damages between the business-as-usual (BAU) emissions path and the optimal risk compliant path. This lower bound applies to the willingness to pay (WTP) of any individual who would agree to the swap, regardless of the degree of risk aversion. A mildly risk averse person would be willing to pay a bit more, a strongly risk averse person would pay much more. If each individual applies a constant relative risk aversion (CRRA) utility function, popular among economists, then the sum of these functions is not CRRA. Conversely, assuming an aggregate CRRA utility function challenges the

\footnotetext{
${ }^{1}$ According to the theory of rational decision (Savage 1954), the preferences of a rational individual can be uniquely represented as expected utility, where the utility function is determined up to the choice of an anchor value at zero and unit. The concepts of subjective probability and utility are meaningful for individual choice. The Condorcet voting paradox shows that straightforward preference aggregation produces intransitivities. Arrow's impossibility theorem shows that there is no acceptable way of representing a group of rational individuals as a rational preference scheme obeying Savage's axioms. Hence group preferences cannot be represented as expected utility (Arrow 1950).
} 
modeler to explain how this function arises from aggregating individual utility functions. The risk swap approach avoids the problem of deriving or otherwise justifying a group utility function.

We calculate this lower bound using the 2009 Excel version of the integrated assessment model (IAM) DICE, created by William Nordhaus. Calculations of damages are performed out to 2205 in tenyear periods. We follow the 2010 US government social cost of carbon analysis focusing only on damages, restricting uncertainty quantification to climate sensitivity, and applying discount rates of 2.5\%, $3 \%$ and 5\%. Commensurate with the simplified uncertainty quantification, the optimal risk compliant emissions path is computed by assuming a simple quadratic cost abatement function; an exponential abatement cost function is used for comparison. Alternatively, the optimal risk compliant path could be selected judgmentally, without making abatement cost considerations explicit. Basing the lower bound risk premium on damages comports with an implicit abatement cost estimation.

Given the total price for the risk swap, the question arises how to apportion the willingness to pay (WTP) value over periods in order to have a per period, per ton estimate of the lower bound on our WTP to meet our risk constraint. The Shapley cost allocation method (Roth and Verrecchia 1979; Roth 1988) is applied for this purpose, treating emitters in various periods as members of potential coalitions to achieve the emissions reduction target. The Shapley approach gives the average contribution of each period to meeting the risk constraint and is thus a natural way to apportion our total WTP over the total emissions reductions.

This approach can serve as a complement to utility-based discussions of social risk aversion. The calculations are intended to illustrate the method and are constrained in two significant respects. First, the uncertainty quantification with regard to climate change is restricted in conformity with the 2010 US government social cost of carbon analysis, and falls well short of a state of the art structured expert judgment quantification (Cooke 2011). Second, the cost abatement function used to determine the optimal risk compliant emissions path incorporates no learning and no uncertainty. The approach differs from other approaches in positing a risk swap, and in requiring explicit uncertainty quantification.

Per ton carbon, the minimum WTP to meet the constraint beginning in 2015, in 2008 USD, is \$106 with a discount rate of 2.5\%, \$64 for a discount rate of 3\%, and \$12 for a discount rate of 5\%. Since one ton CO2 contains 12/44 tons carbon, these values convert to \$29, \$17, \$3 per ton CO2. The marginal damages along the optimal risk constrained path are \$248, \$177 and \$64 per GtC respectively for the three discount rates. In as much as society agrees to pay both costs, our minimum WTP to meet the risk 
constraint and the marginal damages once on the risk constrained path gives \$354, \$241 and \$76 per GtC for the three discount rates. This can be compared to the marginal damages along BAU, which for 2015 are computed to be $\$ 276$, $\$ 196$, and $\$ 69$ per GtC for the three discount rates. As can be seen, at low discount rates the risk constrained approach produces values that are about $30 \%$ higher than the marginal damages at the BAU, and the ratio decreases as the discount rate increases. Per ton $\mathrm{CO} 2$ these convert to \$96, \$66 and \$21 for the risk constrained path, versus \$75, \$53 and \$19 for BAU.

The next section demonstrates that the reduction in expected damages is a lower bound on WTP to reduce risk. Section 3 develops the risk constraint and operationalizes it within DICE. Section 4 presents the results of the Shapley value approach in a deterministic framework, while Section 5 adds uncertainty over the climate sensitivity. Section 6 concludes.

\section{Abatement as Insurance against Climate Damages}

It is straightforward to show that a risk averse individual would be willing to pay at least the reduction in expected damages for an insurance policy, or any other risk reduction measure. Focusing on insurance reflects a familiar way of thinking about risk. The insurance analogy does not go further than this; clearly, a key feature of climate change is that the risks are not diversifiable or insurable in any market.

Consider a risk averse individual with initial wealth $\mathrm{W}$ facing a risk that could cause $\mathrm{X}$ amount of damage. Both $\mathrm{W}$ and $\mathrm{X}$ are measured in dollars. The individual could purchase insurance that fully reimburses damages at price $P$, that is, (s)he could trade their current risk for one with a reduced variance through the purchase of an insurance policy. (S)he will choose to do this if the utility U(.) with the policy is greater than their expected utility without it:

$$
\mathrm{U}(\mathrm{W}-\mathrm{P}) \geq \mathrm{EU}(\mathrm{W}-\mathrm{X})
$$

The individual will be willing to pay for this policy until their utility with the policy just equals their expected utility without the policy. Denote the price of this policy by $\mathrm{P}^{*}$. Since the individual is riskaverse, $\mathrm{U}($.$) is concave, so by Jensen's inequality:$

$$
\mathrm{U}(\mathrm{E}(\mathrm{W}-\mathrm{X})) \geq \mathrm{EU}(\mathrm{W}-\mathrm{X})=\mathrm{U}\left(\mathrm{W}-\mathrm{P}^{*}\right)
$$


And thus, since $\mathrm{U}$ is an increasing function,

$$
\mathrm{W}-\mathrm{EX} \geq \mathrm{W}-\mathrm{P}^{*} \text {, or } \mathrm{E}(\mathrm{X}) \leq \mathrm{P}^{*} \text {. }
$$

As is intuitive, the lower bound on a risk-averse individual's willingness to pay is the expected damages.

This simple set-up is easy to follow, yet we assumed throughout that the wealth, $\mathrm{W}$, was fixed. If wealth is not fixed, a more complicated set-up is required, but the end result is the same. Consider an insurance policy to reduce, but not eliminate, a risk. This can be seen by examining the cumulative distribution functions (cdfs) of the initial risk and the potential trade for a lower risk. In Figure 1, the solid line is a damage cdf representing an initial risk. This could be traded for the risk given by the dashed cdf with lower expected damages and lower variance. Trading the solid risk for the dashed risk is not free, however. The minimal premium an insurance company would charge is the difference in expectations between the solid and dashed risks. Assume the cost for this trade is $\$ 100$. Adding this cost to the dashed cdf has the effect of moving the dashed cdf to the right, generating the dotted cdf. When the two shaded areas between the dotted and solid curves are equal, then the expected damages between the two curves are equal, yet risk-averse individuals prefer the dotted curve as it generates higher utility. Their utility function is concave and the expected utility of a lower variance risk is greater than the expected utility of a higher variance risk with the same expectation ${ }^{2}$.

\section{Figure 1: Cumulative distribution functions}

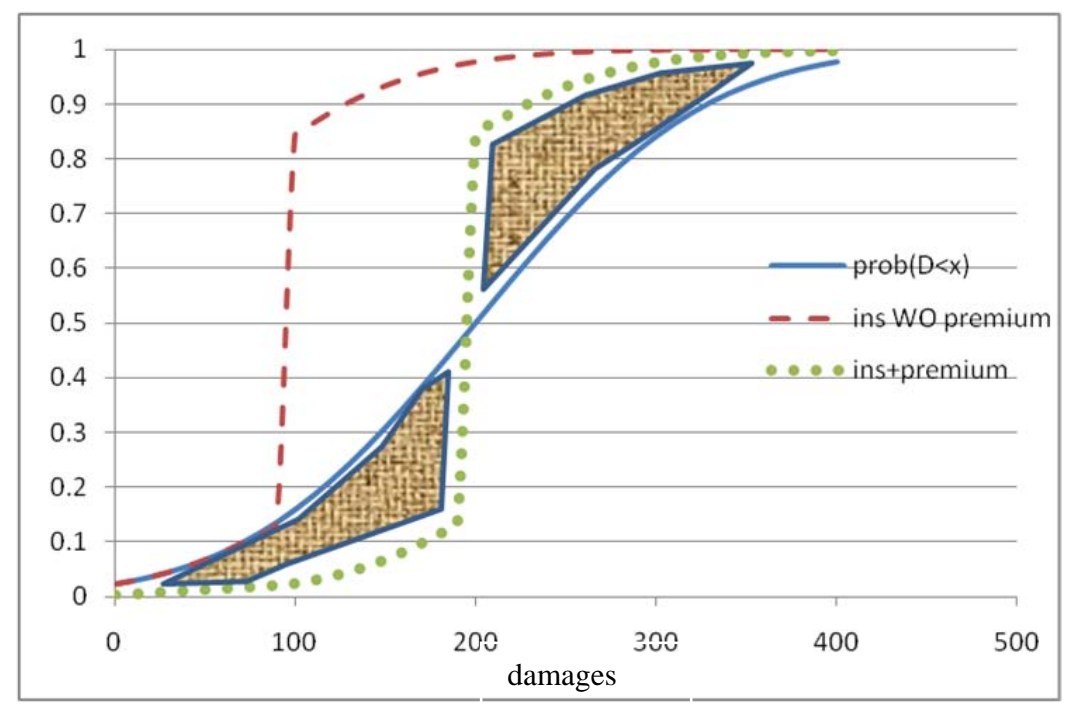

\footnotetext{
${ }^{2}$ This is an approximation based on neglecting higher order terms in the Taylor expansion of $U(X)$ around the expectation of $\mathrm{X}$.
} 


\section{A Risk Constraint for Emissions}

This type of risk trading can be used to conceptualize the climate change problem. Society currently owns a risk corresponding to the business-as-usual (BAU) scenario. Many authors have advocated insurance against climate risks (Tol and Yohe 2006). In this paper we define our risk constraint as limiting warming to $2^{\circ} \mathrm{C}$, as this was articulated in the Copenhagen Accord. Such a constraint can only be met probabilistically. Since the Copenhagen Accord did not specify the probability with which society wants to achieve this target, we follow Anderson and Bows (2011), who interpret the statement to mean no more than a $5 \%$ to $33 \%$ chance of exceeding the $2{ }^{\circ} \mathrm{C}$ target. This would imply that the probability of staying under the target in 200 years should be between 0.67 and 0.95 . The average 0.81 is used for this exercise. Hence, the risk constraint is: "minimize expected costs while keeping the risk of exceeding $2^{\circ} \mathrm{C}$ in 200 years less than 0.19."

The analysis is done using the 2009 Excel version of DICE (Nordhaus 2008) and follows the2010 US government social cost of carbon analysis (Interagency Working Group on Social Cost of Carbon 2010) approach of probabilizing the climate sensitivity parameter. This paper adopts a log-normal distribution for climate sensitivity. We followed the U.S. government SCC analysis statements in interpreting the IPCC's Fourth Assessment Report as indicating a median value of 3 degrees $\mathrm{C}$ per $\mathrm{CO}_{2}$ doubling and a 67\% confidence interval of 2 to 4.5 C. All other DICE parameters are held at their default values. Clearly, many of these assumptions could be questioned and varied; a subject for further work. The point of this paper is simply to demonstrate a risk-constrained approach.

With these assumptions, the BAU path leads to a median temperature increase in 200 years of $5.6^{\circ} \mathrm{C}$, with a $95^{\text {th }}$ percentile of warming of $6.6^{\circ} \mathrm{C}$. There is negligible chance of meeting the risk constraint. This is shown in the left-hand panel of Figure 2. The right-hand figure shows the cdf of temperature in 200 years for the DICE welfare-optimized path, given our assumptions. This path has a less than $5 \%$ chance of meeting the risk constraint we have adopted in this paper. 
Figure 2: Temperature Distribution in 200 years for BAU (left) and DICE optimized (right). The horizontal axis is maximum temperature in $\mathbf{2 0 0}$ years, the vertical axis is cumulative probability.

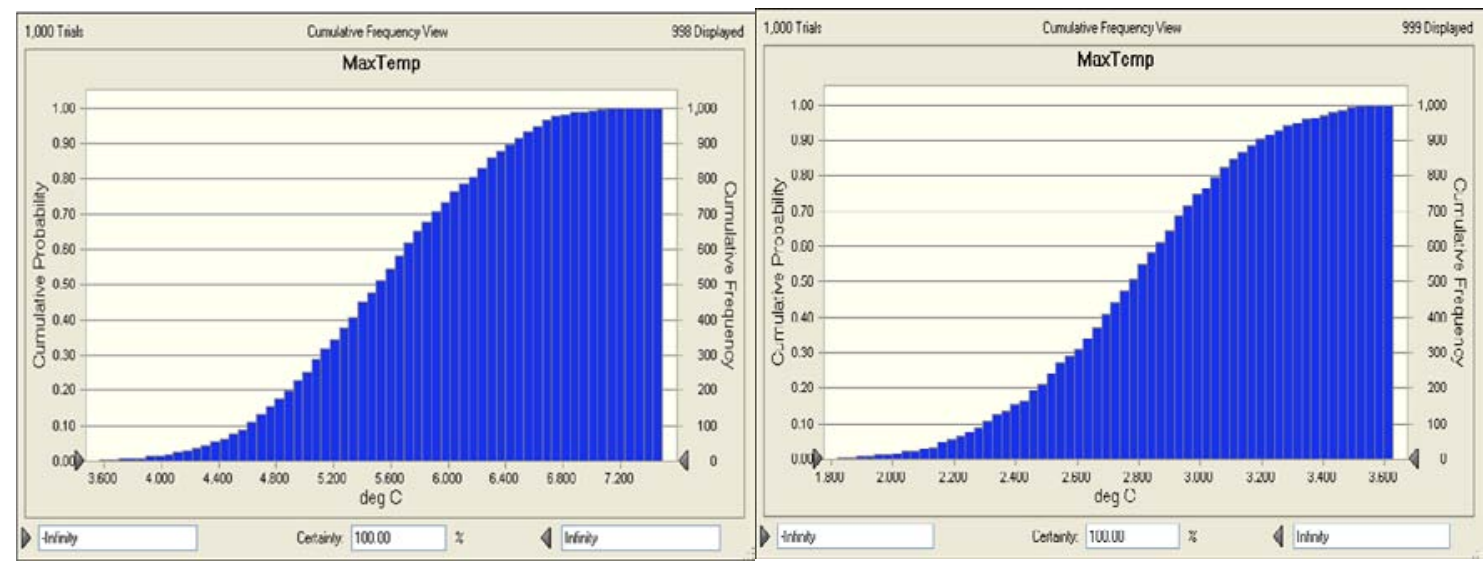

There are many possible emissions paths that could meet our risk target. Society would obviously prefer the least-cost path. In line with the simplified representation of climate uncertainty, we adopt a simplified cost abatement function whereby costs of abatement are proportional to the square of the abated amount. This cost function does not depend on time, does not incorporate learning, and does not have any uncertain parameters. Given this cost abatement function, we must find an emissions path which minimizes abatement costs among all paths satisfying the risk constraint. A straightforward approach to this problem would search all 20-vectors of emissions satisfying the risk constraint and pick the one with lowest cost. The key difficulty is parametrizing the set of emissions paths satisfying the risk constraint. We are aided in this by the observation that the maximum temperature is practically determined by the total emissions, so long as these emissions are not concentrated at the end of the 2005-2205 time period. The abatement cost function in combination with temporal discounting makes this option prohibitively expensive. Using total emissions as a proxy for maximum temperature reduces our cost optimization to simple line search. The optimization procedure is then as follows.

1. Choose a cost abatement function, a discount rate, an error acceptance value $\varepsilon>0$ and adjustment value $\delta>0$

2. Choose a maximum total emissions $M$

3. Find an emissions path that minimizes costs over the 2015-2205 horizon under the constraint that the total emissions is equal to $\mathrm{M}$

4. Repeatedly sample the climate sensitivity distribution and determine the probability P of exceeding $2^{\circ} \mathrm{C}$ with the chosen emissions path (1000 samples are used for this step)

5. If $\mathrm{P}>19 \%+\varepsilon$, put $\mathrm{M}=\mathrm{M}-\delta$ and go to (2); if $\mathrm{P}<19 \%-\varepsilon$ put $\mathrm{M}=\mathrm{M}+\delta$ and go to (2).

6. Stop 
The XL solver was used in step 3 and performed well. The min cost risk compliant emissions path depends on the discount rate. For discount rate $2.5 \%$, the cumulative distribution of the maximum temperature over 2005-2205 is shown in Figure 3. The total emissions along this path is $43 \mathrm{GtC}$. For different discount rates, the same total emissions applies; that is, adjusting the total emissions so that the min cost path satisfying the risk constraint with equality, for different discount rates, leads to the same value of $43 \mathrm{GtC}$. This reinforces the supposition that the maximum temperature is driven by the total emissions.

Figure 3 Cumulative distribution for maximum temperature for min cost risk compliant emissions path for $2.5 \%$ discount rate

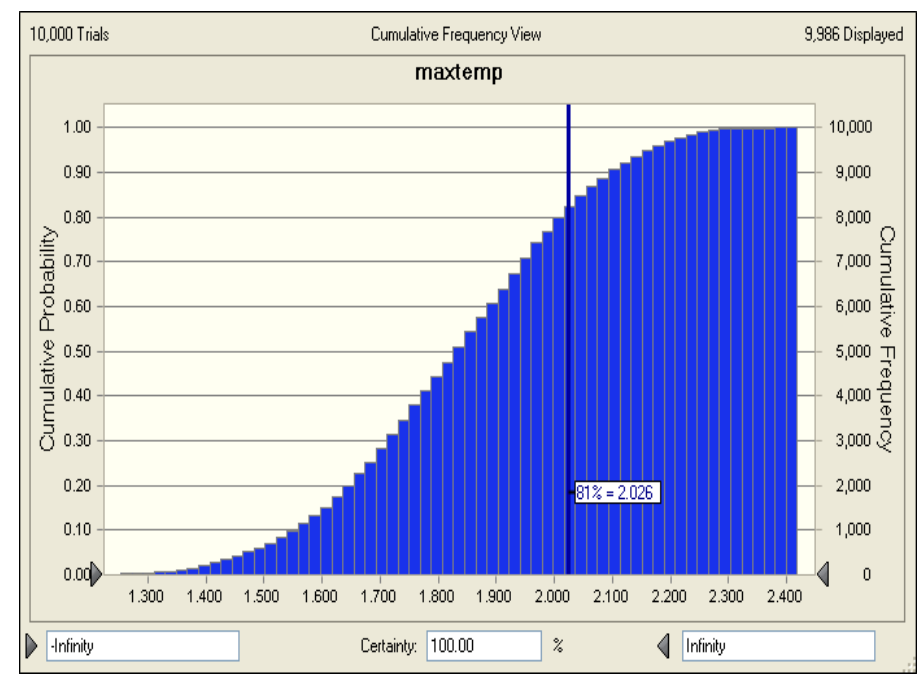

Table 1 shows the min cost emissions paths for discount rates $2.5 \%$ and $5 \%$, and compares these with the DICE BAU and DICE optimal paths. 
Table 1: Emissions and Damages for Four Paths; Emissions are in GtC and damages are in \$Trillion.

\begin{tabular}{|c|c|c|c|c|c|c|c|c|}
\hline & $\begin{array}{c}\text { BAU } \\
\text { Emissions }\end{array}$ & $\begin{array}{c}\text { BAU } \\
\text { Damages }\end{array}$ & $\begin{array}{l}\text { Min cost } \\
\text { emissions, } \\
2.5 \% \\
\text { discount }\end{array}$ & $\begin{array}{l}\text { Min cost } \\
\text { damages } \\
2.5 \% \\
\text { discount }\end{array}$ & $\begin{array}{l}\text { Min cost } \\
\text { emissions, } \\
5 \% \\
\text { discount }\end{array}$ & $\begin{array}{l}\text { Min cost } \\
\text { damages } \\
5 \% \\
\text { discount }\end{array}$ & $\begin{array}{c}\text { DICE } \\
\text { Opt } \\
\text { Emissions }\end{array}$ & $\begin{array}{l}\text { ICE Opt } \\
\text { Damages }\end{array}$ \\
\hline 2005 & 9.06 & 0.10 & 9.06 & 0.10 & 9.06 & 0.10 & 9.06 & 0.10 \\
\hline 2015 & 10.46 & 0.24 & 5.62 & 0.23 & 8.20 & 0.24 & 8.96 & 0.24 \\
\hline 2025 & 12.39 & 0.56 & 6.18 & 0.46 & 8.67 & 0.51 & 9.99 & 0.52 \\
\hline 2035 & 14.57 & 1.17 & 6.58 & 0.86 & 8.43 & 0.99 & 10.84 & 1.06 \\
\hline 2045 & 16.74 & 2.28 & 6.49 & 1.46 & 6.62 & 1.73 & 11.23 & 1.94 \\
\hline 2055 & 18.72 & 4.08 & 5.56 & 2.30 & 2.02 & 2.67 & 11.03 & 3.27 \\
\hline 2065 & 20.39 & 6.77 & 3.49 & 3.33 & 0.00 & 3.66 & 10.22 & 5.07 \\
\hline 2075 & 21.70 & 10.51 & 0.01 & 4.40 & 0.00 & 4.58 & 8.89 & 7.32 \\
\hline 2085 & 22.59 & 15.35 & 0.00 & 5.35 & 0.00 & 5.41 & 7.15 & 9.88 \\
\hline 2095 & 23.16 & 21.28 & 0.00 & 6.18 & 0.00 & 6.12 & 5.15 & 12.56 \\
\hline 2105 & 23.36 & 28.20 & 0.00 & 6.87 & 0.00 & 6.74 & 3.04 & 15.14 \\
\hline 2115 & 22.64 & 35.78 & 0.00 & 7.40 & 0.00 & 7.21 & 0.93 & 17.29 \\
\hline 2125 & 22.15 & 43.78 & 0.00 & 7.79 & 0.00 & 7.58 & 0.08 & 18.89 \\
\hline 2135 & 21.45 & 51.97 & 0.00 & 8.08 & 0.00 & 7.86 & 0.06 & 19.98 \\
\hline 2145 & 20.63 & 60.14 & 0.00 & 8.30 & 0.00 & 8.07 & 0.05 & 20.68 \\
\hline 2155 & 19.66 & 68.12 & 0.00 & 8.45 & 0.00 & 8.24 & 0.04 & 21.09 \\
\hline 2165 & 18.62 & 75.76 & 0.00 & 8.58 & 0.00 & 8.37 & 0.03 & 21.30 \\
\hline 2175 & 17.53 & 82.96 & 0.00 & 8.67 & 0.00 & 8.48 & 0.02 & 21.39 \\
\hline 2185 & 16.40 & 89.64 & 0.00 & 8.75 & 0.00 & 8.58 & 0.02 & 21.39 \\
\hline 2195 & 15.25 & 95.75 & 0.00 & 8.82 & 0.00 & 8.67 & 0.02 & 21.34 \\
\hline 2205 & 14.08 & 101.26 & 0.00 & 8.89 & 0.00 & 8.75 & 0.01 & 21.27 \\
\hline
\end{tabular}

The probabilistic constraint entails emissions restrictions that are significantly more stringent than the DICE optimum, as is to be expected. The higher discount rate pushes the emissions forward, also as expected. 


\section{The Shapley Value for Apportioning the Lower Bound on WTP to Meet the Risk Constraint}

Damages from climate change are caused by emissions over a sequence of years. We compute damages over a time horizon of 200 years and discount them back to the year 2015. In time periods $1 \ldots \mathrm{n}$, let the emissions from the BAU scenario be $e_{1}, e_{2} \ldots e_{n}$, and let $r_{1}, \ldots r_{n}$ denote the emissions from the risk constrained path. Let $d_{j}$ be the damages in period $\mathrm{j}$. Assume first that the damages are known with certainty. Without temporal discounting overall damages are:

$$
D\left(e_{1}, \ldots e_{n}\right)=d_{1}\left(e_{1}\right)+d_{2}\left(e_{1}, e_{2}\right), \ldots+d_{n}\left(e_{1}, e_{2} \ldots e_{n}\right) .
$$

Damages in period 1 are caused by period 1 emitters, damages in period 2 are caused by period 1 and period 2 emitters, etc. Letting $D_{\rho}$ denote the net present value of damages discounted at rate $\rho$, we impose discounting by replacing (4) with:

$$
D_{\rho}\left(e_{1}, \ldots e_{n}\right)=\sum_{t=1 \ldots n} e^{-\rho(t-1)} d_{t}\left(e_{1}, \ldots e_{t}\right) .
$$

We assume $d_{i}(0,0, . .0)=0$. The damage is non-linear in temperature, temperature is non-linear in emissions.

The lower bound on WTP is $D\left(e_{1} \ldots e_{n}\right)-D\left(r_{1}, \ldots r_{n}\right)$; or with discounting, $D_{\rho}\left(e_{1} \ldots e_{n}\right)-D_{\rho}\left(r_{1}, \ldots r_{n}\right)$. This amount is not paid all at once and we thus consider how this value should be apportioned over the periods. Simply dividing these total damages by total emissions ignores the fact that the effects of emissions are cumulative, and ignores temporal discounting. Because of the non-linearity of the damage function, the amount attributed to $\mathrm{e}_{1}$ will depend on the amount emitted in the other periods. One strategy would be to let period $i$ pay for the damages caused by emitting $e_{i}$ instead of $r_{i}$, given that all previous periods $1 \leq \mathrm{j}<\mathrm{i}$, emitted $\mathrm{r}_{\mathrm{j}}$. The damages apportioned to initial periods are high because they are added to high values of emissions in later periods. This apportioning scheme is termed Initially High. The unit rate calculation scheme is shown in Table 3 below.

Table 3: Initially High damage apportioning scheme with discount rate $\rho$

\begin{tabular}{|l|l|}
\hline Period 1 & $\left(D_{\rho}\left(e_{1} \ldots e_{n}\right)-D_{\rho}\left(r_{1}, e_{2} \ldots e_{n}\right)\right) / e_{1}$. \\
\hline Period 2 & $\left(D_{\rho}\left(r_{1}, e_{2} \ldots e_{n}\right)-D_{\rho}\left(r_{1}, r_{2}, e_{3} \ldots e_{n}\right)\right) / e_{2}$ \\
\hline$\cdots$ & $\cdots$ \\
\hline Period $n$ & $\left(D_{\rho}\left(r_{1}, r_{n-1}, e_{n}\right)-D_{\rho}\left(r_{1}, \ldots r_{n}\right)\right) / e_{n}$ \\
\hline
\end{tabular}


Alternatively, we could have let period i pay for the damage that would caused by emitting $\mathrm{e}_{\mathrm{i}}$, given that all subsequent periods $\mathrm{j}, \mathrm{i}<\mathrm{j} \leq \mathrm{n}$ emitted $\mathrm{r}_{\mathrm{j}}$. The damages apportioned to initial periods are low because they are added to low values of emissions of later periods. This apportioning scheme is termed Initially Low. The unit rate calculation scheme is shown in Table 4 below.

\section{Table 4: Initially Low damage apportioning scheme with discount rate $\rho$}

\begin{tabular}{|l|l|}
\hline Period 1 & $\left(D_{\rho}\left(e_{1}, r_{2}, \ldots r_{n}\right)-D_{\rho}\left(r_{1}, \ldots r_{n}\right)\right) / e_{1}$ \\
\hline$\ldots$. & $\ldots$ \\
\hline Period $n-1$ & $\left(D_{\rho}\left(e_{1} \ldots e_{n-1}, r_{n}\right)-D_{\rho}\left(e_{1} \ldots e_{n-2}, r_{n-1}, r_{n}\right)\right) / e_{n-1}$ \\
\hline Period $n$ & $\left(D_{\rho}\left(e_{1} \ldots e_{n}\right)-D_{\rho}\left(e_{1} \ldots e_{n-1}, r_{n}\right)\right) / e_{n}$ \\
\hline
\end{tabular}

If we multiply the unit rates in Tables 3 or 4 by the emissions in each period, then the total NPV of damages, $D_{\rho}\left(e_{1} \ldots e_{n}\right)-D_{\rho}\left(r_{1}, \ldots r_{n}\right)$, equals the sum of the NPV of damages assigned to each period. However, because damages are non linear in emissions, the damages in each period are not the same in Tables 3 and 4 . The first table leads a higher contribution for the first period than the second table, and conversely for the last period.

Note that Table 4 could be obtained from Table 3 by reversing the order in which the various periods switch from the BAU to the risk compliant paths. In Table 3, period 1 is the first to switch, in Table 4, period 1 is the last to switch. Evidently, any ordering would produce a cost allocation whose sum is $D_{\rho}\left(e_{1} \ldots e_{n}\right)-D_{\rho}\left(r_{1}, \ldots r_{n}\right)$.

Lower bounds WTP apportioned over periods according to these two schemes are shown in Table 5. Since the calculations are terminated at year 2205, later years' emissions are not projected as far forward as those of earlier years, resulting in a truncation bias ${ }^{3}$. Nonetheless, it is apparent from Table 5 that these two apportioning schemes lead to different schedules of payments. It is also apparent that neither scheme is obviously more appropriate than the other.

\footnotetext{
${ }^{3}$ The truncation bias could be removed by computing a running Shapley value using a moving 200 year window. For initial periods, however the differences are slight. At 2.5\% discount, the present value of a dollar in 2205 is $\$ 0.007$.
} 
Table 5: Initially High / Low values for Min Cost risk compliant path,[\$/tC]

\begin{tabular}{||c|c|c||}
\hline \multicolumn{3}{|c|}{$\begin{array}{c}\text { Min Cost risk compliant } \\
\text { emissions }\end{array}$} \\
\hline & $\begin{array}{l}\text { Discount rate 2.5\% } \\
\text { High }\end{array}$ & $\begin{array}{l}\text { Initially } \\
\text { Low }\end{array}$ \\
\hline 2015 & 121 & 108 \\
\hline 2025 & 122 & 113 \\
\hline 2035 & 122 & 117 \\
\hline 2045 & 123 & 122 \\
\hline 2055 & 125 & 127 \\
\hline 2065 & 129 & 134 \\
\hline 2075 & 135 & 140 \\
\hline 2085 & 115 & 119 \\
\hline 2095 & 96 & 98 \\
\hline 2105 & 79 & 80 \\
\hline 2115 & 64 & 64 \\
\hline 2125 & 50 & 50 \\
\hline 2135 & 39 & 38 \\
\hline 2145 & 29 & 29 \\
\hline 2155 & 21 & 21 \\
\hline 2165 & 15 & 14 \\
\hline 2175 & 9 & 9 \\
\hline 2185 & 5 & 5 \\
\hline 2195 & 2 & 2 \\
\hline 2205 & 1 & 1 \\
\hline
\end{tabular}

For a given risk-compliant emissions path, each approach assigns a share of the insurance price to each period based on its position in a unique sequence (coalition) of decisions by other periods, but the choice among sequences is arbitrary. In fact this is one in a class of "n-person” problems. Given a set of axioms proposed by Shapley (1953), there is a unique solution to the cost allocation problem which is found by calculating the average marginal contribution of each period to every possible coalition. 
Notionally, one can think of this as a measure of the share of responsibility that accrues to each period for the damages caused by the BAU, over and above the risk-compliant path.

Let $\pi \in \mathrm{n}$ ! be a permutation of $(1, \ldots n) . \pi(1)$ is the first element under $\pi$. The damage allotted to period i emissions, under permutation $\pi$ is:

$$
D_{\rho}\left(e_{\pi(1)}, . . e_{\pi(i-1)}, e_{\pi(i)}, r_{\pi(i+1)}, \ldots r_{\pi(n)}\right)-D_{\rho}\left(e_{\pi(1)}, . . e_{\pi(i-1)}, r_{\pi(i)}, r_{\pi(i+1)}, \ldots r_{\pi(n)}\right)
$$

We may write this as

$$
\mathrm{D}_{\rho}\left(\mathrm{E}_{\pi(1) \ldots \pi(\mathrm{i}-1)}, \mathrm{e}_{\pi(\mathrm{i})}, \mathrm{R}_{\pi(\mathrm{i}+1) \ldots \pi(\mathrm{n})}\right)-\mathrm{D}_{\rho}\left(\mathrm{E}_{\pi(1) \ldots \pi(\mathrm{i}-1)}, \mathrm{r}_{\pi(\mathrm{i})}, \mathrm{R}_{\pi(\mathrm{i}+1) \ldots \pi(\mathrm{n})}\right)
$$

Averaging the damage allotment for period i over all permutations gives the intended minimum bound payment for period i. This may be seen as the Shapley value for period i in a damage allocation cooperative game: The value of (7) does not depend on the order of the elements $\pi(1), \ldots \pi(\mathrm{i}-1)$, nor on the order of the elements $\pi(\mathrm{i}+1), \ldots \pi(\mathrm{n})$. Any reordering of these two subsets would produce the same value in (7). We therefore define the value $v(\pi(1), \ldots \pi(\mathrm{i}-1))$ of the "coalition" $\{\pi(1), \ldots \pi(\mathrm{i}-1)\}$ as the value $D_{\rho}\left(e_{\eta \pi(1)}, . . e_{\eta \pi(i-1)}, r_{\pi(i)}, r_{v \pi(i+1)}, \ldots r_{v \pi(n)}\right)$, for any permutation $\eta$ of $E_{\pi(1) \ldots \pi(i-1)}$, and any permutation $v$ of $\mathrm{R}_{\pi(\mathrm{i}+1) \ldots \pi(\mathrm{n})}$. The Shapley value for period $\mathrm{i}$ is then:

$$
\begin{gathered}
(1 / n !) \sum_{\pi \in n !} D_{\rho}\left(e_{\pi(1)}, . . e_{\pi(i-1)}, e_{\pi(i)}, r_{\pi(i+1)}, \ldots r_{\pi(n)}\right)-D_{\rho}\left(e_{\pi(1)}, . . e_{\pi(i-1)}, r_{\pi(i)}, r_{\pi(i+1)}, \ldots r_{\pi(n)}\right) \\
=\left(1 / 2^{n_{-} 1}\right) \sum_{S \subset\{1, \ldots n\} \backslash i} v(S \cup i)-v(S) .
\end{gathered}
$$

It follows immediately from (8) that if $\mathrm{e}_{\pi(\mathrm{i})}=\mathrm{r}_{\pi(\mathrm{i})}$, then the differences in damages in (6) are zero, for any permutation $\pi$.

The Shapley value for period $i$ has the virtue that it does not depend on which other periods followed the BAU emissions. This virtue could also be seen as a weakness, as some of the coalitions to which i contributes damages may be judged very unlikely. For example, it may be judged that the emission scheme $\left(e_{1} r_{2}, e_{3}, r_{4}, \ldots\right)$ is quite implausible, and that the contribution $\left[D_{\rho}\left(e_{1} r_{2}, e_{3}, r_{4}, \ldots\right)-D_{\rho}(\right.$ $\left.\left.r_{1} r_{2}, e_{3}, r_{4}, \ldots\right)\right]$ is, therefore, less important to the assessment of period 1's portion of the total cost. On the other hand, without a clear criterion for choosing preferred orderings, there is no alternative to the order 
invariant solution (8). Moreover, these are not real coalitions but virtual coalitions used in determining a cost allocation.

\section{Shapley Values and Marginal Damages under Uncertainty}

The values in Tables 5 are based on the nominal values of the uncertain climate sensitivity, and later years are affected by a truncation bias. In a rigorous study, a joint distribution would be assigned to all uncertain variables based on structured expert judgment. A structured expert judgment exercise has never been performed on such climate models. Failing that, we apply the distribution on climate sensitivity discussed in Section 3. Distributions for the lower bound on WTP in each period and for each discount rate are built up by sampling a climate sensitivity and a random permutation. In light of the truncation bias, Table 6 shows the means and standard deviations only for the first 3 periods. Values are given as $\$ / G t C$ and $\$ / G t C O 2$. These results are dependent on the abatement cost function. Table 7 shows results using an exponential abatement cost function. For low discount rates the values are rather close, but for high discount rates, emissions reductions are moved more into the future resulting in lower initial values and higher values further out.

Table 6: Means and standard deviations of insurance price with quadratic abatement costs for three discount rates and three periods, in 2008 USD, uncertain climate sensitivity.

\begin{tabular}{|c|c|c|c|c|c|c|c|}
\hline \multicolumn{8}{|c|}{ Insurance Lower Bound Insurance Price, quadratic abatement cost function } \\
\hline & & \multicolumn{3}{|c|}{$2008 \$ / G t C$} & \multicolumn{3}{|c|}{$2008 \$ / G t C O 2$} \\
\hline & & \multicolumn{3}{|c|}{ Discount rate } & \multicolumn{3}{|c|}{ Discount rate } \\
\hline & & 0.025 & 0.03 & 0.05 & 0.025 & 0.03 & 0.05 \\
\hline \multirow[t]{2}{*}{2015} & mean & 106 & 64 & 12 & 29 & 17 & 3 \\
\hline & stdev & 47 & 26 & 4 & 13 & 7 & 1 \\
\hline \multirow[t]{2}{*}{2025} & mean & 109 & 67 & 14 & 30 & 18 & 4 \\
\hline & stdev & 47 & 27 & 5 & 13 & 7 & 1 \\
\hline \multirow[t]{2}{*}{2035} & mean & 111 & 70 & 16 & 30 & 19 & 4 \\
\hline & stdev & 47 & 28 & 5 & 13 & 8 & 1 \\
\hline
\end{tabular}


Table 7: Means and standard deviations of insurance price with exponential abatement costs for three discount rates and three periods, in 2008 USD, uncertain climate sensitivity.

\begin{tabular}{||l|l|c|c|c||}
\hline \multicolumn{5}{||c||}{$\begin{array}{c}\text { Insurance Price lower bound, exponential cost } \\
\text { abatement, 2008\$/GtC }\end{array}$} \\
\hline \hline \multirow{2}{*}{2015} & mean & 92 & 2 & 0 \\
\cline { 2 - 5 } & stdev & 40 & 1 & 0 \\
\hline \multirow{2}{*}{2025} & mean & 117 & 96 & 72 \\
\cline { 2 - 5 } & stdev & 50 & 39 & 9 \\
\hline \multirow{2}{*}{2035} & mean & 129 & 109 & 24 \\
\cline { 2 - 6 } & stdev & 54 & 44 & 8 \\
\hline \hline
\end{tabular}

If we are on a risk compliant emissions path, there is no WTP to reduce risk since society is already on a risk-constrained path. There will, however, still be marginal damages of carbon emissions on this path. Table 8 shows these marginal damages for the min cost paths for each discount rate, for quadratic abatement costs.

Table 8: Means and standard deviations of marginal damages along risk compliant path with quadratic cost abatement, for three discount rates and three periods, uncertain climate sensitivity

\begin{tabular}{|c|c|c|c|c|c|c|c|}
\hline \multicolumn{8}{|c|}{ Marginal damages, quadratic abatement cost function } \\
\hline & & \multicolumn{3}{|c|}{$2008 \$ / G t C$} & \multicolumn{3}{|c|}{$2008 \$ / G t C O 2$} \\
\hline & & \multicolumn{3}{|c|}{ Discount rate } & \multicolumn{3}{|c|}{ Discount rate } \\
\hline & & 0.025 & 0.03 & 0.05 & 0.025 & 0.03 & 0.05 \\
\hline \multirow[t]{2}{*}{2015} & mean & 248 & 177 & 64 & 68 & 48 & 17 \\
\hline & stdev & 112 & 75 & 21 & 31 & 21 & 6 \\
\hline \multirow[t]{2}{*}{2025} & mean & 233 & 163 & 52 & 64 & 44 & 14 \\
\hline & stdev & 104 & 68 & 17 & 28 & 19 & 5 \\
\hline \multirow[t]{2}{*}{2035} & mean & 216 & 146 & 41 & 59 & 40 & 11 \\
\hline & stdev & 96 & 61 & 14 & 26 & 17 & 4 \\
\hline
\end{tabular}

The sum of the lower bound on WTP and the SCC of the risk-constrained path are compared with the marginal damages along the BAU in Table 9. The marginal damages of the BAU are about are from $12 \%$ 
to $28 \%$ smaller than the sum of the lower bound payment and the marginal damages in the risk compliant scenarios. The differences decrease in the discount rate and increase with time. Both the lower bound on WTP and the marginal damages are computed as a dollar per ton of carbon in various time periods. However, the two values differ in significant ways. Unlike the marginal damages, the lower bound on WTP involves comparison between the BAU and a risk compliant emissions path which expresses society's desire to avoid risks. If the BAU were already a risk compliant path, then the lower bound on WTP would be zero, while the marginal damages would still be positive. On the other hand, as the damages from the BAU go up, so does the WTP, since meeting the risk constraint now requires greater damage reductions.

Table 9: Total costs of risk compliant path with quadratic loss and marginal damages of BAU for three discount rates, in GtC and GtCO2

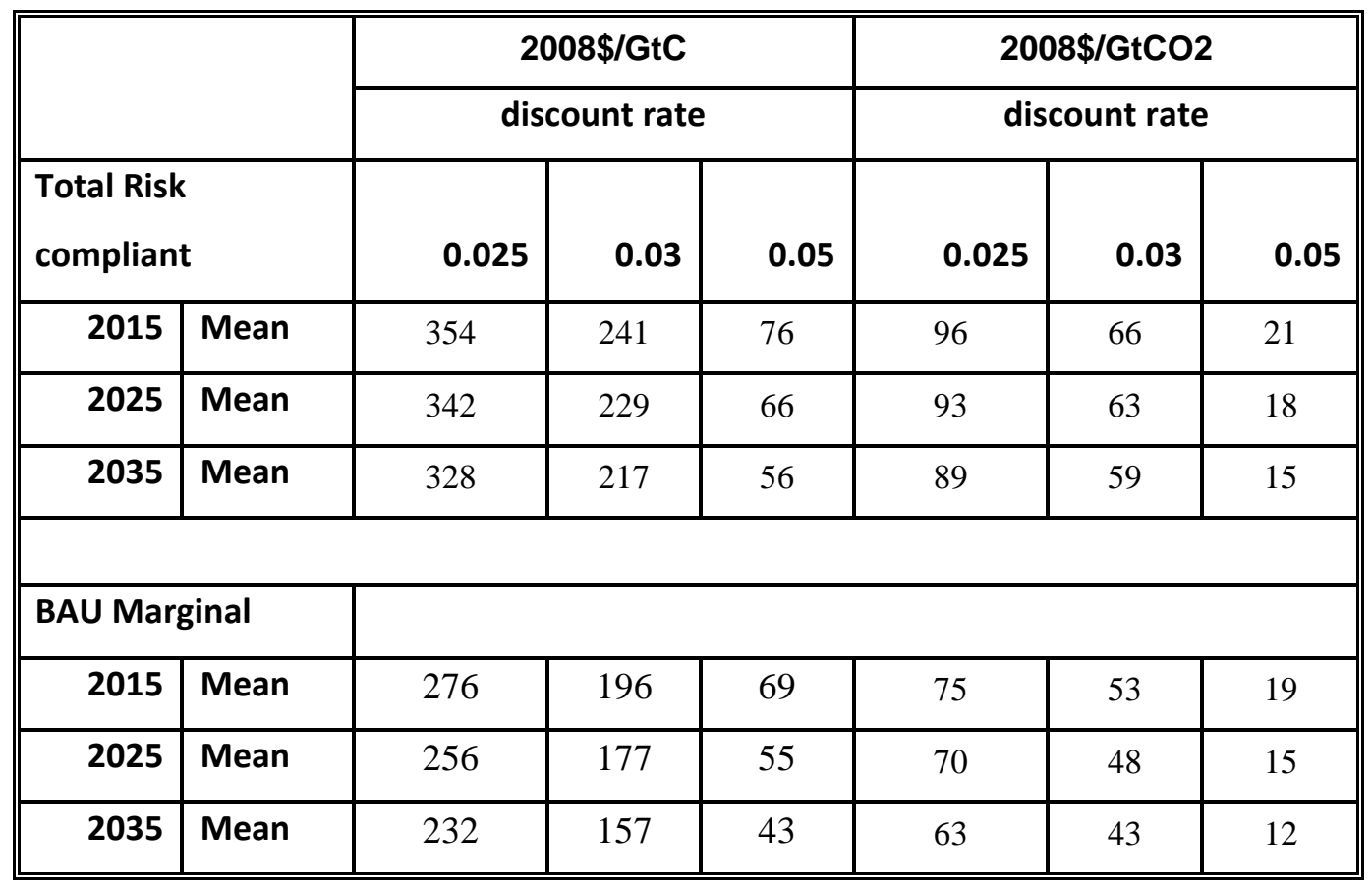

\section{Conclusions}

Society's risk aversion is inferred from international agreements which, in effect, stipulate a risk constraint: the probability of raising global mean temperatures by more than $2^{\circ} \mathrm{C}$ in 200 years should not exceed 19\% (Anderson and Bows 2011). A lower bound on a virtual climate risk insurance price is a lower bound on our willingness to pay for a virtual insurance policy that swaps our BAU climate risk for 
one that complies with this risk constraint. Computing this value requires a quantification of uncertainty for climate parameters. The optimal risk compliant emissions path is computed by minimizing a quadratic abatement cost function under a probabilistic constraint. Other abatement cost functions could be used, or indeed the optimal risk compliant path could be chosen in a heuristic manner without making abatement cost assumptions explicit. If the current BAU path had complied with the risk constraint, the risk premium would be zero, and it increases as the distance between the BAU and risk compliant path increases. The optimal risk compliant emissions path still incurs marginal damages of carbon emissions. The sum of the marginal damages along the optimal risk compliant path and the virtual insurance premium we should pay for the risk swap are between $10 \%$ and $30 \%$ higher than the marginal damages along the BAU. The Shapley value is used to apportion the total insurance price over the emitters in the various periods.

These calculations are primarily intended to illustrate an accounting method that prices risk. They are limited by the restricted uncertainty quantification used to find an optimal risk compliant path, and by the limited cost abatement function. They are also conditioned on the climate and damage modeling in DICE2009.

Acknowledgement: The author gratefully acknowledges helpful comments by Robert Kopp, Carolyn Kousky, Dallas Burtraw and Harrison Fell. This work was funded by the U.S. Department of Energy Office of Policy \& International Affairs, the U.S. Climate Change Technology Program, with additional support from NSF grant \# 0960865. It does not reflect the official views or policies of the United States government or any agency thereof.

\section{References}

Anderson, K. and A. Bows (2011). "Beyond 'dangerous' climate change: emission scenarios for a new world " Philisophical Transactions of the Royal Society A 369: 20-33.

Arrow, K.J., "A Difficulty in the Concept of Social Welfare", Journal of Political Economy 58(4) (August, 1950), pp. 328-346

Cooke, R.M. (2011) “Uncertainty analysis comes to integrated models for climate change...and conversely”. RFF draft.

Interagency Working Group on Social Cost of Carbon (2010). Social Cost of Carbon for

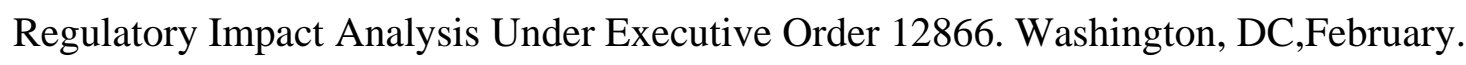


Kousky, C. Kopp, R.E. and Cooke R.M. (2011) "Risk Premiums and the Social Cost of Carbon: A Review” Resources for the Future

Mendelsohn, R. (2008). "Is the Stern Review an Economic Analysis?" Review of Environmental Economics and Policy 2(1): 45-60.

Nordhaus, W. (2007). The Challenge of Global Warming: Economic Models and Environmental Policy. New Haven, CT, Yale University.

Nordhaus, W. (2008). A Question of Balance: Weighing the Options on Global Warming Policies New Haven, CT, Yale University Press.

Roth, A. E. and R. E. Verrecchia (1979). "The Shapley value as applied too cost allocation: a reinterpretation." Journal of Accounting Research 17(1).

Roth, A. E., Ed. (1988). The Shapley Value: Essays in Honor of Lloyd S. Shapley. New York, NY, Cambridge University Press.

Savage, L.J. (1954) The Foundations of Statistics. John Wiley \& Sons., 1954.

Shapley, L.S. 1953. “A Value for n-Person Games.” In H. Kuhn and A. W. Tucker, eds. Contribution to the Theory of Games II, pp. 307-317. Princeton: Princeton University Press.

Tol, R.S. and Yohe, (2006) “A review of the Stern Review” World Economics, vol. k7 No. 4 October-December, 233-250.

Weitzman, M. L. (2009). "On Modeling and Interpreting the Economics of Catastrophic Climate Change." Review of Economics and Statistics 91(1): 1-19.

Yohe, G. and R. Tol (2008). "The Stern Review and the economics of climate change: an editorial essay." Climatic Change 89(3): 231-240. 


\section{Conomics}

The Open-Access, Open-Assessment E-Journal

Please note:

You are most sincerely encouraged to participate in the open assessment of this discussion paper. You can do so by either recommending the paper or by posting your comments.

Please go to:

http://www.economics-ejournal.org/economics/discussionpapers/2011-17

The Editor 